\title{
A Collaborative Virtual Environment for Situated Learning of Car Driving
}

Citation for published version (APA):

Miao, Y., Pinkwart, N., \& Hoppe, U. (2007). A Collaborative Virtual Environment for Situated Learning of Car Driving. International Journal on Advanced Technology for Learning (ATL), 3(4), 233-240.

https://doi.org/10.2316/JOURNAL.208.2006.4.208-0894

DOI:

10.2316/JOURNAL.208.2006.4.208-0894

Document status and date:

Published: 26/03/2007

Document Version:

Peer reviewed version

Please check the document version of this publication:

- A submitted manuscript is the version of the article upon submission and before peer-review. There can be important differences between the submitted version and the official published version of record. People interested in the research are advised to contact the author for the final version of the publication, or visit the DOI to the publisher's website.

- The final author version and the galley proof are versions of the publication after peer review.

- The final published version features the final layout of the paper including the volume, issue and page numbers.

Link to publication

\section{General rights}

Copyright and moral rights for the publications made accessible in the public portal are retained by the authors and/or other copyright owners and it is a condition of accessing publications that users recognise and abide by the legal requirements associated with these rights.

- Users may download and print one copy of any publication from the public portal for the purpose of private study or research.

- You may not further distribute the material or use it for any profit-making activity or commercial gain

- You may freely distribute the URL identifying the publication in the public portal.

If the publication is distributed under the terms of Article $25 f a$ of the Dutch Copyright Act, indicated by the "Taverne" license above, please follow below link for the End User Agreement:

https://www.ou.nl/taverne-agreement

Take down policy

If you believe that this document breaches copyright please contact us at:

pure-support@ou.nl

providing details and we will investigate your claim.

Downloaded from https://research.ou.nl/ on date: 26 Apr. 2023 


\title{
A COLLABORATIVE VIRTUAL ENVIRONMENT FOR SITUATED LEARNING OF CAR DRIVING
}

\author{
Y. Miao*, N. Pinkwart**, and H.U. Hoppe*** \\ * Educational Technology Expertise Centre \\ The Open University of the Netherlands, Heerlen, The Netherlands \\ yongwu.miao@ou.nl \\ ** Human Computer Interaction Institute \\ Carnegie Mellon University, Pittsburgh, USA \\ nielsp@cs.cmu.edu \\ *** Institute for Computer Science and Interactive Systems \\ The University of Duisburg-Essen, Duisburg, Germany \\ hoppe@collide.info
}

\begin{abstract}
In the view of situated learning theory, knowledge and understanding are fundamentally products of learning situations. Learning is situated and takes place by means of legitimate peripheral participation within the context of a community of practice. Based on the theory of situated learning, this article develops conceptual and technical approaches to build a webbased collaborative 3D car-driving simulation environment that requires only low computing, networking and development resources. Rather than instructing individuals on a formal, structured, intensive and programmed base, this simulation environment supports members of virtual communities of practice to perform informal, unstructured, spontaneous, collaborative, situated learning. Pilot studies conducted with the system show its partial success and demonstrate that it depends on the characteristics of specific educationally valuable learning situations whether the collaborative learning approach we propose can succeed also with smaller group sizes.
\end{abstract}




\section{Key words}

Situated learning, computer simulation, collaborative virtual environment, car-driving training

\section{Introduction}

Constructivist conceptions of learning assume that knowledge is individually constructed and socially co-constructed by learners based on their interpretations of experiences in the world. Since knowledge cannot be transmitted but is actively built, instruction should consist of creating situations that provide interpretable experiences. In particular, students learn best when they are actively engaged in acquiring and constructing knowledge in a learning-by-doing situation. However, sometimes the instruction method of learning-by-doing is difficult to apply because of costs, safety requirements, or resource unavailability. Many researchers and educational practitioners believe that virtual reality simulation systems offer strong benefits that can support education through their experiential and intuitive characteristics in which learners can share contexts and interact [1] and especially facilitate constructivist and situated learning [2, 3]. Many 3D simulation systems for training purposes have been developed and are in regular use, allowing students to experience a "real-life" situation in an artificial environment. The use of simulation systems demonstrates several practical advantages and offers enhanced training possibilities [4, 5]. In the view of Gredler [1], simulations can "bridge the gap between the classroom and the real world by providing experience with complex, evolving problems.” Gredler distinguishes between several types of educational simulations: experiential ones in which the student is part of the simulated world and can interact with it, and symbolic ones in which the student acts as a researcher and observes the simulated world.

Virtual worlds and simulations can serve for a variety of educational functions, including the design of interactive training systems and the design of experiential learning environments, and can deliver effective learning support (see [2] for a comprehensive survey). Many educational simulation systems emphasize the importance of physical factors to facilitate the training process. For example, a typical car-driving simulator usually contains all necessary hardware and software modules, an advanced visual and audio system, a motion system, and a fully functional cab with instrumentation to provide a "reallife" driving environment. Such "vehicle-centred" simulators emphasize the simulation of the physical motion and sense. These simulators are designed to train learners to control the vehicle. Furthermore, to achieve some traffic conditions, series of traffic scenarios are usually elaborately designed and programmed [6]. Because these kinds of simulation systems are very expensive, the training programs involving these simulators are typically formal, structured, and intensive courses.

Today however, for some training purposes, low-cost simulation systems (also called "homebrew” or “desktop” systems in the terminology of [7]) can be developed and used as well, as the performance of personal computers increases. 
Recently many companies have acknowledged this and have developed low-cost simulation systems for training purposes. For example, a 3D driving school [8] has been developed as a software application running on a single PC with a simple user interface. Different from "vehicle-centred" approaches, such a kind of simulator is "traffic-centred" and focuses on simulating traffic situations. It can be used to train at high-level skills such as recognizing situations and developing driving strategies. According to [9], a considerable part of training tasks (approx. 60\%) can be done with these kinds of simulators. Although a low-cost training simulation system clearly has a different focus compared to "full size" solutions, the training procedures are often similar. An individual trainee uses a simulation system with standard, pre-defined driving scenarios. The system or an instructor gives commands and monitors the performance of the trainee. If the trainee has completed a set of scenarios without mistakes, the system will present to him scenarios with increasing difficulty. If an error is committed, feedback will be presented to the trainee during the lessons, and the trainee may need to drive through the same series of scenarios repeatedly until he succeeds.

Our research work described in this article follows a different educational paradigm: we provide a collaborative virtual simulation environment that supports informal, unstructured, spontaneous, collaborative, situated learning. Rather than adopting a "drill and practice" approach for teaching specific driving skills, our environment fosters users to learn traffic rules and basic knowledge about car-driving in virtual communities of practice. Instead of repeatedly presenting hard-coded situations, the geographically distributed users themselves create potentially rich and unexpected situations at runtime, like those that occur in the real world. In the terminology of [1], our approach integrates two subtypes of experiential simulations: social-process simulations (interacting with peer drivers) and diagnostic simulations in virtual environments (steering the car according to traffic rules). Learners can access the simulated world and gain driving knowledge anytime and anywhere like playing a collaborative game. Our first attempt in this direction has been described in [10], which focuses on discussing a "high-dimensional data object” method to represent situated knowledge. In this article, we focus on presenting educational and technical approaches to a web-based, low-cost 3D collaborative virtual simulation environment for car driving, and present some initial evaluation results.

\section{Requirements Derived from Situated Learning Theory}

Situated learning places the learner in the centre of an instructional process consisting of content - the facts and processes of the task; context - the situations, values, beliefs, and environmental cues by which the learner gains and masters content; community - the group with which the learner will create and negotiate meaning of the situation; and participation - the process by which learners working with peers and with experts in a social organization solve problems related to everyday life circumstances $[11,12,13]$. Situated learning in a virtual learning environment should integrate these four elements: 
content, context, community, and participation. In this section, we discuss the first two elements in subsection 2.1 and the other two elements in the remaining two subsections, respectively.

\subsection{Supporting Contextualised Learning}

Learner experience, learner control and learner interpretation as well as an emphasis on authentic environmental and contextual factors are increasingly recognised as important factors for teaching and learning [14]. Knowledge similarly indexes the situation in which it arises and is used. The embedding circumstances efficiently provide essential parts of its structure and meaning. Learners interact with the world not following preconceived plans but related to the situations encountered. Learning the situatedness of knowledge is as important as learning knowledge itself. An approach to a virtual learning environment should therefore provide an authentic context and embed content in authentic situations.

\subsection{Supporting Collaborative Learning}

Lave and Wenger [15] have proposed situated learning as an analytical perspective on learning. Situated learning takes place within the context of a community of practice. Lave and Wenger are reacting to modern-day schooling with its emphasis on academic achievement and its aloofness from activities as they actually take place within a community: "More importantly, the organization of schooling as an educational form is predicated on claims that knowledge can be decontextualised, ...” [15] Through involvement in a community, learners interpret, reflect, and form meaning. Community provides the setting for the social interaction that is needed to engage in dialogue with others to see various and diverse perspectives on any issue [15, 16]. Community is the joining of practice with analysis and reflection to share the tacit understandings and to create shared knowledge from the experiences among participants in a learning opportunity. A virtual learning environment should thus provide shared activity spaces for members of the community of practice to interact with each other and to socially coconstruct knowledge.

\subsection{Supporting Participation and Scaffolding}

Participation is a process by which learners working together with peers and with experts in a social organization solve problems related to everyday life circumstances $[11,12,13]$. While working on these tasks, a learner may receive instruction as needed to complete tasks or understand aspects of the domain knowledge. Scaffolding allows students to perform tasks that would normally be slightly beyond their ability without that assistance from the teacher. A virtual learning environment should focus on creating authentic activity and on posing authentic problems to the students to solve, including the necessary scaffolding and instruction to help the student engage in the problems as early as possible. 


\section{Educational and Technical Approaches to a Web-based, Low-cost 3D Collaborative Virtual Simulation Environment}

With the pedagogical background of situated learning theory and its general implications on the design of educational targeted collaborative simulation environments as outlined above, this section presents a design of a concrete collaborative car driving simulator that takes into account these principles. In particular, we set the focus on the aspects of "content and context" and "social interaction”. On the technical level, these are partially in conflict with each other: realistic content and context requires a rich data model, while in turn the desired fast interaction with peers in a distributed system demands a reasonably small amount of data to transmit in order to reduce the network load, especially if a "low cost" solution is also aimed at in terms of bandwidth.

\subsection{Embedding Content in Situations}

The computational objects needed for a low-cost but still "authentic" collaborative car driving simulator can be subdivided into two categories: static objects (e.g., houses or trees) and dynamic objects (cars, pedestrians, etc.). The virtual driving place model we employ consists of a grid of small cells, each cell containing a list of static and dynamic objects together with some generic parameters (position of the cell in the grid, etc.). For the cars, a predefined abstract data model together with its transformation to VRML representation is used. The parameters incorporated in this model are position, direction and speed of the car, turning angle, acceleration/braking information (needed for the break lights), indicator status, and sector information. As in a real car, the user can manipulate certain of these parameters directly (e.g., braking information or indicator status) and others indirectly (like speed or position information). The simulation environment updates the car data model according to the user actions and updates the central data storage (cf. next subsection) as well as the local view.

Conceptually, the described static and dynamic objects in the driving place constitute the "situated knowledge" embedded in a concrete traffic situation in a road network that is used by multiple cars. We have chosen Jess [17], a rule based logic programming language as a technical platform to encode these objects. While the basic facts used within the Jess engine are immediate consequences of the atomic objects and their properties, the production rules serve different purposes:

- A number of rules serve the purpose of situation recognition. Here, location-bound situations never change their position (e.g., a curve), while non-location-bound situations (e.g., a car approaching another car) can happen anywhere. These situations serve as the key for all the other rules and also for the feedback mechanism, as they encode content and context of a specific task the student has to solve. E.g., speeding in a curve is associated to the "curve" situation, and the 
safety distance is related to the "approaching a car" situation. Situations can be nested and parallel, as it is of course possible that a car approaches another car and a junction at the same time.

- Target facts and rules describe how the outcome of specific situations should be. For instance, they encode that the indicator should be used in the "junction with turning" situation. If a target state is reached, this is saved in the user model to represent the learner's growing ability to deal with the related situation.

- $\quad$ Finally, control rules are used to represent whether the student has actually reached any of his current targets or not.

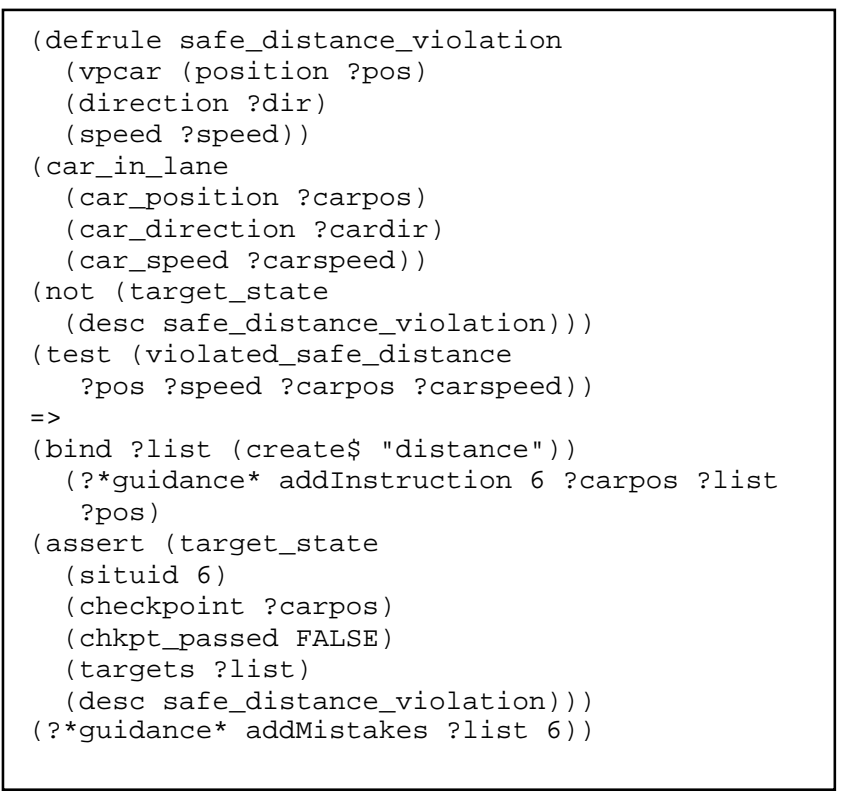

\section{Figure 1. A Jess rule example}

Fig. 1 shows a simplified version of a situation for the "violation of safety distance" situation. The condition part of the situation states that this situation has not been recognized yet and that the distance to a car driving in front is too small compared to the speed. The result part of the rule builds a target state (which is input for target rules) and specifies some parameters for the guidance system (cf. section 3.3).

\subsection{Enabling Social Interaction}

While the system components as described up to here essentially enable single users to use the driving simulator, an important ingredient for fully adopting the situated learning approach is collaboration support. This can naturally be done by allowing multiple users to simultaneously drive on a shared driving space. As a system foundation, we have chosen the TSpace system [18], a tuple space based solution, due to its proximity to the Jess based fact/rule architecture: tuples in the space can simply be conceived as fact lists in Jess. Fig. 2 illustrates how the students and the teacher, each of them on their local PCs, interact with the remote tuple space. It is visible that the manipulation of traffic lights is done on a dedicated 
teacher PC, whereas the collision detection (as a specific case of a situation) is done in a distributed manner. The "moving car” tuples in the TSpace are created by the student's actions (or by artificial driver agents on the teacher machine) furthermore, the tuple space also serves statistical purposes in error counting and thereby updating the user models.

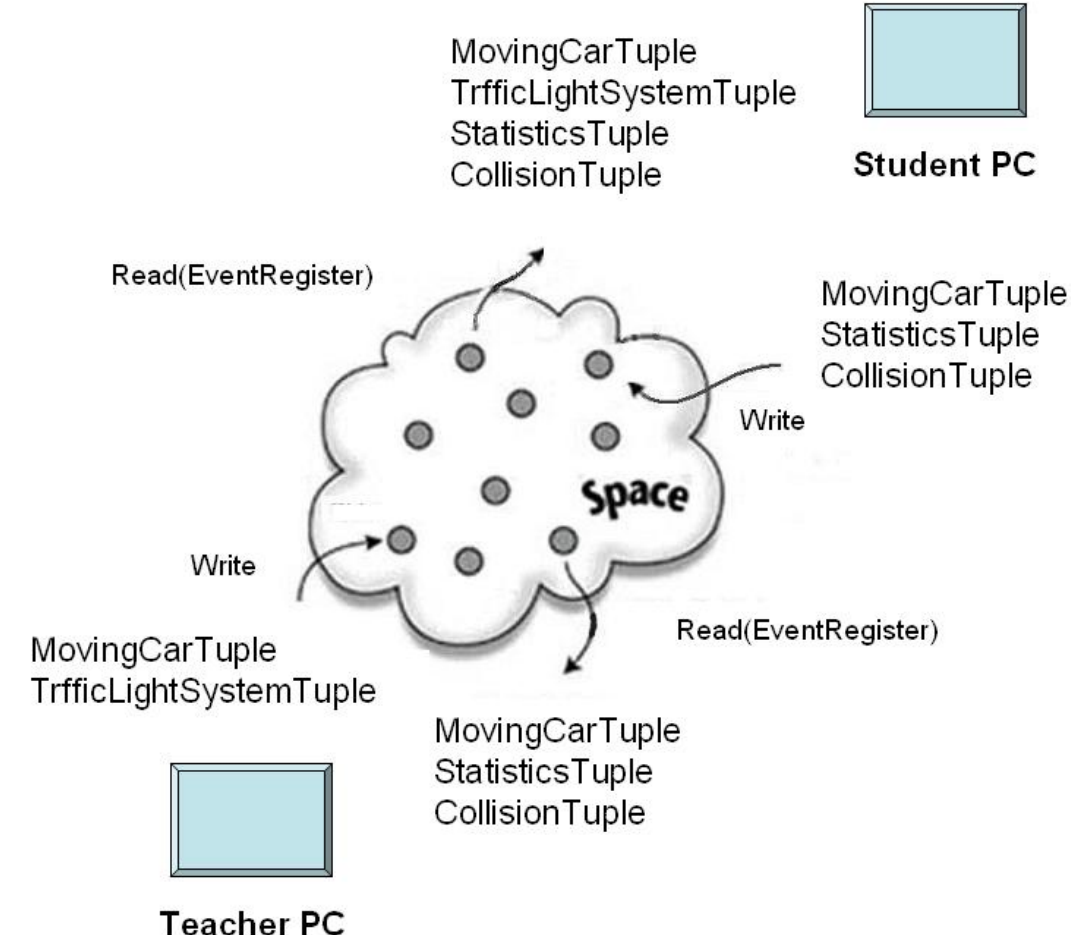

Figure 2. Interactions with the tuple space

With this technical approach to support distribution and synchronization, an educational approach to support informal, unstructured, and spontaneous collaboration has been developed. There are two ways to foster social interaction between right users. First, multiple users can "sit" in the same virtual car. Unlike a realistic car, a virtual car can have unlimited "seats" (in theory) and can be entered and left when it is moving. The people in the same car can have different roles (e.g., coach, trainee, and observer), which have different rights to control the car. They can switch their roles at any time they want. Audio connections with the users in the same car will be automatically set up and maintained when the users enter and leave a shared car. Because the screens of users sitting in the same car are coupled in a WYSIWIS (what you see is what I see) manner, they have the same learning context. When a user asks a question about the current situation, they can discuss immediately without describing an abstract situation in a way normally used in classrooms. Second, it is possible to establish audio connections between the users whose cars are in a near distance. Each car has a unique number shown on the front and back. Other people can request to establish an audio connection to a car by dialling its number. When the users in this car accept the request, an audio connection between these cars will be set up. All users in these two cars can then hear each other. 
This is a very useful mechanism to group people for collaboration. For example, when several cars approach the same junction and the drivers do not know who has the right of way, they can connect to each other and discuss the current situation. Another example is to group people who are involved in an accident or are witness. They may discuss whose fault the accident was and how to avoid it in the same or a similar situation. A log file recording the accident can be saved as a case. The case indexed by the situation can be retrieved and replayed later on. In the replay, users can even can exchange cars to repeatedly observe the same procedure from different perspectives.

\subsection{Providing Situated Guidance}

The educationally oriented collaborative car driving simulator as described before can already be used in a situated learning approach. Users of the system can drive a virtual car in virtual driving places in a way similar to driving in the real world. They will encounter unexpected and rich situations and are meanwhile involved in creating training scenarios for others. In addition, a human coach can select one of the students' cars to enter. After entering a car, the coach can provide situated instructions like in the real world. When the human coach is not available, the Jess based situation representation invites also computer based guidance add-ons. To allow for personalized feedback, these rely on a situation-based user model which captures the user's performance records about past situations. Whenever a situation is encountered, the system will examine whether the user has knowledge and skills to handle this situation based on the statistics records of this situation. According to the user's preference information, the system can then provide guidance in an appropriate mode. Three modes of providing guidance are described below:

- Forewarn or hint: if a situation occurs that the user can not correctly deal with, the system actively hints the user what he should take care of and how to behave.

- Simple feedback: the system monitors the performance of the students. If any error is committed, the system will show the feedback to the user and update the user model.

- Guidance on demand: a user, who may have little experience in a situation, can actively seek help. Then, the system will provide guidance (technically, this is a simplified version of the first usage mode).

\section{A Prototype System}

In order to demonstrate the feasibility of our approach, we have implemented and tested a prototype system. This prototype is completely in line with the research goals and theoretical framework of situated learning, but (due to resource limitations), has some restrictions. For example, the driving place model and the car model are graphically rather simple. Also the level of 
detail in the graphics and the rendering quality can still be improved. Furthermore, the number of the modelled situations is currently limited (though, of course, the system is open to additions here). Users can currently act by keyboard input only more advanced steering options are not implemented yet. In addition, the mechanism to automatically set up and maintain audio connections has not been implemented. However, the main purpose of the system is fulfilled: we can support learningby-collaborative-simulations. The users not only entertain with driving in a collaborative virtual environment, but also learn and apply driving knowledge and apply knowledge in virtual communities of practice.

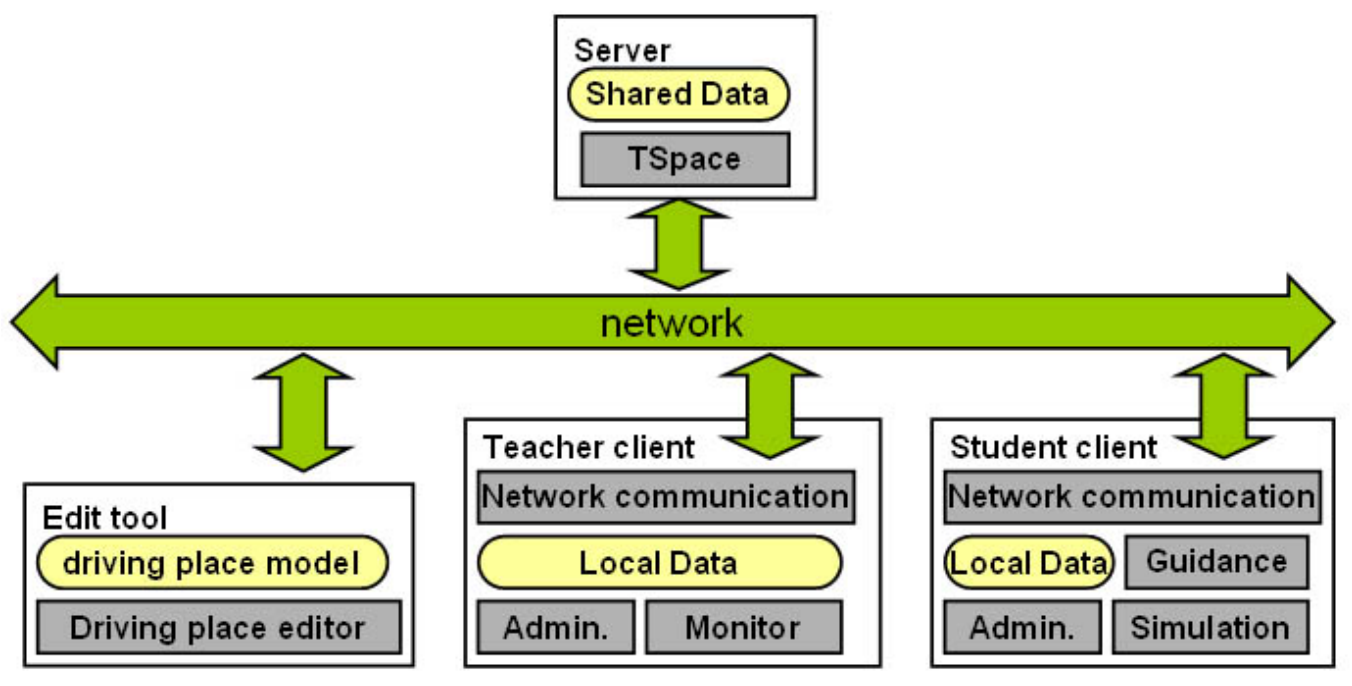

Figure 3. System modules and components

Fig. 3 illustrates the general software architecture of the prototype system. It consists of four communication modules: the map editing tool, the teacher client, the student client, and the server. These modules communicate in a clientserver architecture via a network. Each communication module has software components (grey) and the data components (light-grey). Driving place models can be edited using the edit tool and saved in the database. Teachers can set up a collaborative virtual environment by creating a session and loading a desired driving place model. Students then register and join the session by using an administration component. The student client will then connect with the groupware server via a communication component. After creating a connection, the student client will get the updated data from the server. Then the student can see the view of the driving place from the perspective of his/her car. The student controls the virtual car by input actions via the keyboard. User actions are handled by the simulation component. The state of the car in the local data will be changed and will be sent to the server. The latter broadcasts changes to other student clients. Each client will render the view based on the updated data. The teacher client has more options: the teacher can monitor all student cars in the driving place. On the teacher client, it is possible to find any student car and couple the teacher's view with the view of the corresponding student. Thus, the teacher can coach the student for driving in a way like in the real world. In case that the human coach is not 
available, the computer-based guidance system will provide situated instructions in a textual form (see Fig. 4) in one of modes listed in section 3.3.

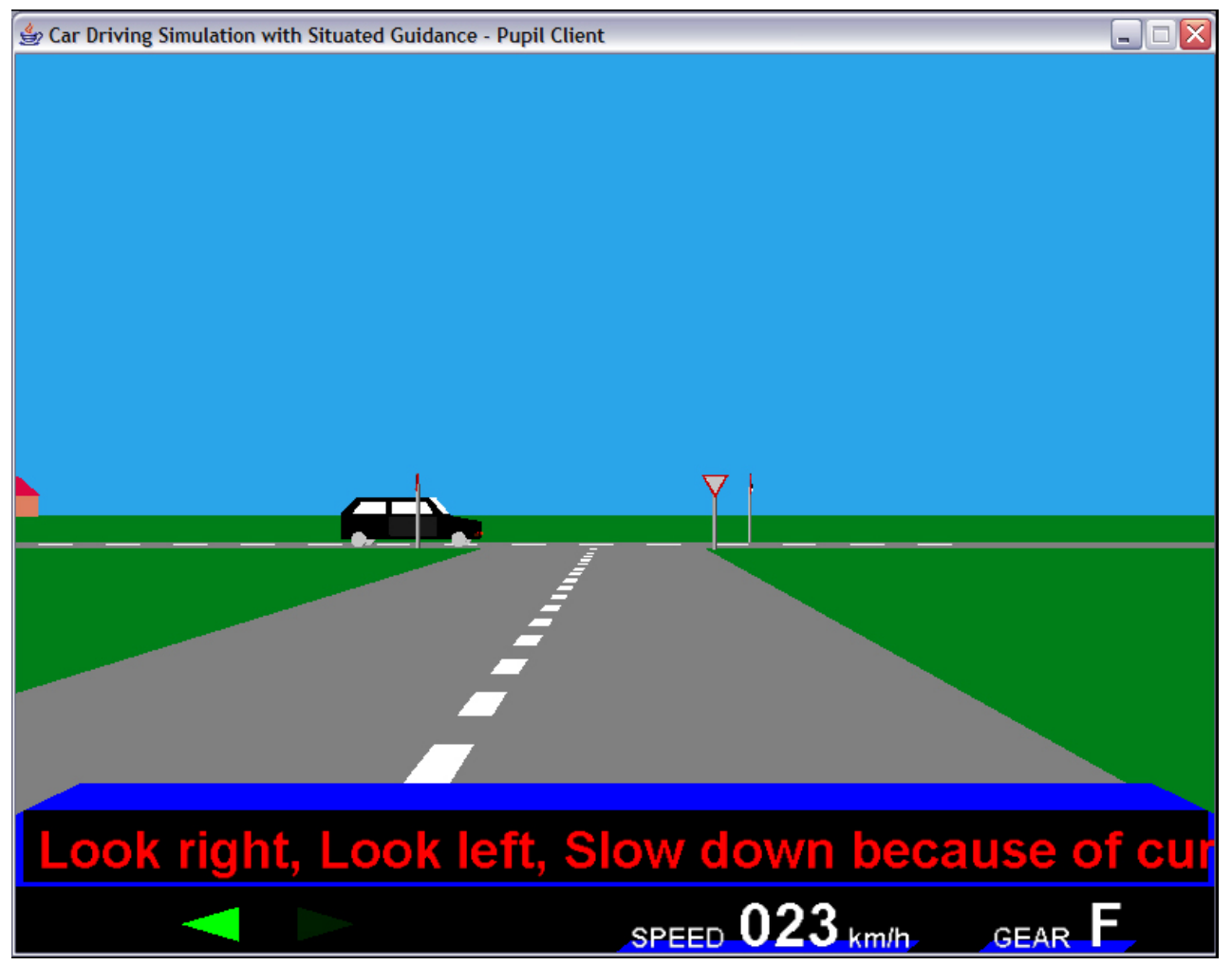

Figure 4. Screenshot of a view with guidance

As mentioned before, the distinguished characteristics of our approach is that the learning situations are not hardcoded into the simulator but consequences of multiple users driving in a collaborative virtual environment. In existing cardriving simulators, series of situations are usually pre-defined and presented in a certain order repeatedly until the trainee can handle them correctly. The problem is whether the trainee can really handle such situations correctly in different contexts, not only in the repeatedly presented one. In contrast, when learning driving in our simulator, users can potentially encounter rich situations in an unpredictable order like in the real world. When many users with different knowledge levels drive in a shared virtual driving place, the variety of situations and the amount of situation occurrences will be relatively high.

However, if there are not enough drivers in a shared driving place, the number of situations that a learner is likely to experience decreases correspondingly. As a consequence, the learning opportunities will be reduced and learners may feel bored, decreasing their learning interests. In order to solve this problem, we developed an autonomous agent simulating a moving car. The driving knowledge needed for situation detection and provision of guidance represents a way experts handle situations. This knowledge is also used to control the behaviour of the randomly driving agent. As a consequence, such an 
agent behaves like a skilled driver and exactly follows the traffic rules on his randomly chosen route. By introducing these agent-based virtual cars in shared driving places, the traffic can be increased.

\section{Results of Pilot Studies}

While the system as a whole is subject of continuing development, the existing functions have demonstrated the feasibility of our approach. We have tested the already implemented parts of system with multiple clients - technically, the results were promising. The interaction worked smoothly, and also the guidance system was fully functional. Based on these successful usability tests, we ran a pilot evaluation study of the system in order to find out if the approach of replacing hard-coded situations with spontaneous collaborative interactions actually works. Since the effectiveness of the whole situated learning based approach essentially relies on enough learning opportunities, we counted how many learning opportunities students encountered while using the system. Apart from duration of system usage, this of course depends on two main factors: the number of system users and the size of the road map, together determining the traffic density. In our study, we used a relatively small road map with 5 cars on it. This was a density which reflects well modest traffic conditions. We expected this to lead to a reasonable number of learning opportunities.

In the concrete study, 5 groups used the system for 10 minutes each. Each group consisted of 2 human users and 3 randomly driving artificial agents which obeyed all traffic rules but took random walks on the road map. This design models the fact that on realistic roads, beginners are present as well as experienced drivers who rarely make mistakes. The subjects in the pilot study were volunteer students.

To analyze results of the sessions, the number of detected situations of specific types (cf. section 3.1) was counted. In the following presentation and discussion of evaluation results, we focus on three characteristic and interesting situation types which involve more than one car: "traffic junction without right of way", "traffic junction without traffic signs" where we want a student to respect the right of way of another car crossing the junction, and "safety distance to another car".

Our data analysis shows two results. First, the data stresses the importance of group size in these collaborative applications. If we do not consider the agent cars but only the student actors, the average number of created situations was 0.9 for the junction situations and 2 for the safety distance situation. Both values are rather low considering the driving time of 10 minutes, but reflect well what happens on a map with very few cars.

Our second finding is that a larger group size can partially solve this problem but is not sufficient for creating complex situations. Fig. 5, showing the average number of situations with and without randomly driving agents (i.e., 2 or 5 cars) in the test sessions, illustrates this. Although the number of cars was more than doubled, not all situations occurred correspondingly more often. The difference in the "junctions without traffic lights" conditions is statistically not even 
significant. The only considerable increase is the "safety distance" situation ( $\mathrm{t}=3.55, \mathrm{p}<0.01)$, leading to an average of 4.6 situation occurrences during the 10 minutes simulation time.

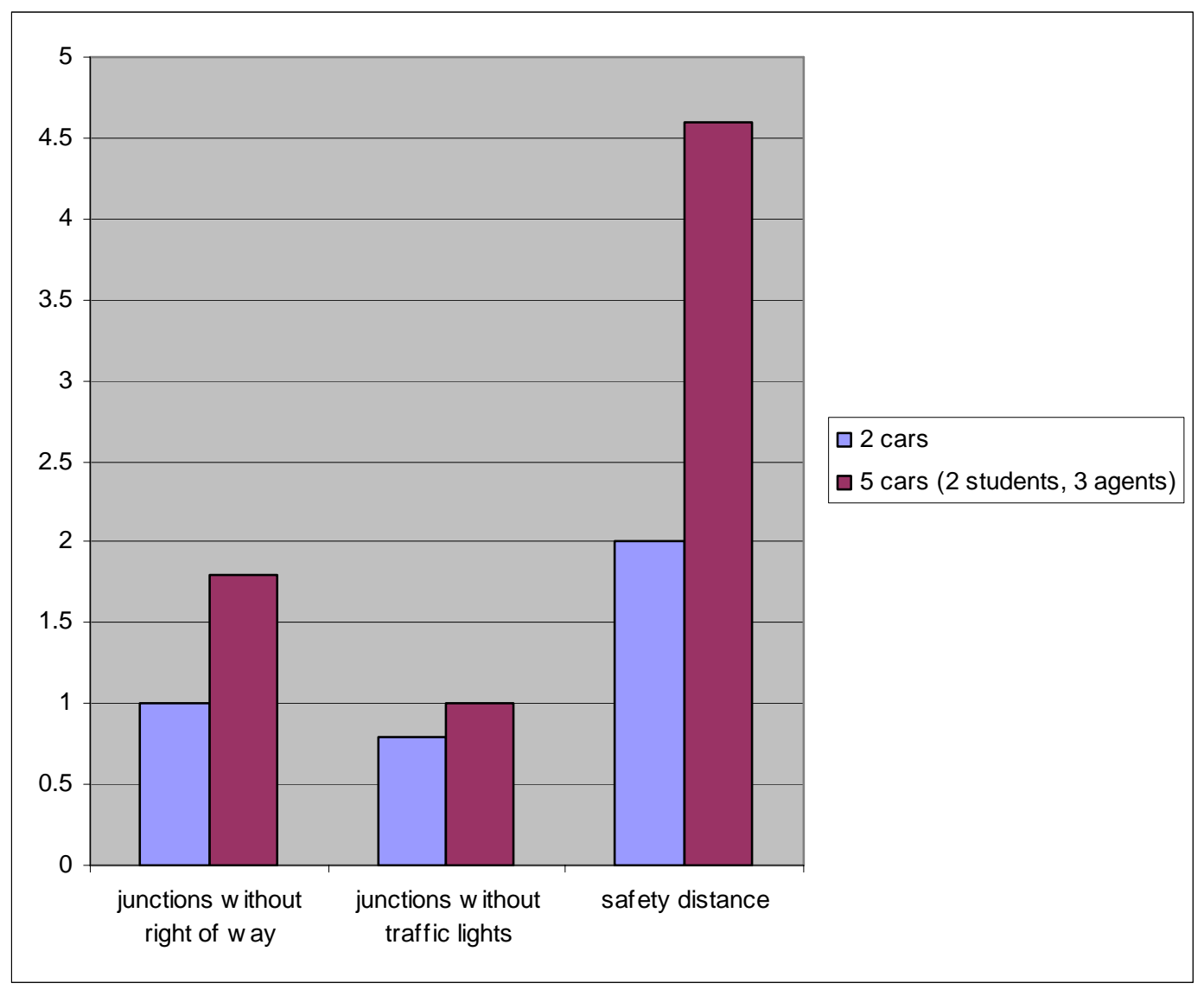

\section{Figure 5. Situation occurrence by traffic density}

This can be explained by the fact that this situation, compared to the others, is relatively simple - a car is very likely to just happen to be in front of another car on the map, thereby creating "safety distance” situations. For the other situation types (junction situations), more specific time constraints have to be fulfilled. It turned out that totally uncoordinated driving did not lead to a high number of these situation occurrences even though the number of drivers was increased.

A conclusion of this study is that, unless really large user groups are involved so that a high traffic density is guaranteed, only some but not all of the interesting learning situations occur frequently. It depends on characteristics of the situation whether or not an increase of traffic density leads to a significant increase of situation occurrences.

\section{Conclusion and Future Work}

Learning to drive a car in the real world is an unsafe process. Training via a fully functional car-driving simulator can be helpful, but is usually associated with high costs for most learners. Furthermore, a lot of conventional driving simulators 
either give no guidance at all, or adopt a “drill and practice” approach. A PC-based car-driving simulation system makes it possible for most users to learn driving knowledge anytime anywhere. Because of the limitation of the PC power and the lack of some devices like motion equipments and large 360 degree screens, it is unrealistic to train all relevant skills in homebrew simulation systems. However, if we focus on training some important aspects of car-driving such as recognising situations, learning traffic rules, low-cost simulation systems are useful as well.

Guided by situated learning theory, we recognised that at minimum, the following requirements should be taken into account while developing a simulation system: supporting contextualised learning, supporting collaborative learning, and supporting participation and scaffolding. In the design of our low-cost 3D simulation system, we meet these three requirements by embedding content in situations, enabling social interactions, and providing situated guidance, respectively. A prototype system has been implemented and pilot studies with multiple users have has demonstrated the feasibility of our idea.

The obvious limitation of our collaboration oriented approach is that there will be fewer interesting learning situations if not enough users are involved in a shared driving place. To address this and in order to support small sized groups in conducting collaborative learning with a certain volume of traffic and rich learning opportunities, we developed a randomly driving agent. The result of our pilot study shows that the traffic density was indeed increased after introducing the randomly driving agents, but the number of challenging learning situations the students encountered did not increase as much as we hoped for. This might be overcome with a different agent design: the randomly driving agents move around in a shared driving place following the traffic rules with randomly selected routes. They have no intentions to help learners and are not “challenging” enough. In order to improve our simulation system and provide more learning opportunities for learners, we plan to develop a kind of pedagogical agent which will intentionally create appropriate situations for users. In addition, more situation types and alternate forms of guidance (e.g., verbal instructions and augmented graphics) will be designed and implemented in the system. Furthermore, an audio communication management with flexible channel controls is planned to be integrated into the system. This will allow learners to collaborate when they sit in the same car or/and are in different cars. With these additions, serious evaluations will be conducted.

\section{Acknowledgements}

Thanks to Hasna Boussairi, Michael Nahhas, Sebastian Ruiling, Oliver Schilbach, Tobias Schloesser, and Sabine Zill for their development of the prototype systems and the provision of materials. 


\section{References}

[1] M.E. Gredler, Games and simulations and their relationships to learning. In D. H. Jonassen (Ed.), Handbook of research

for educational communications and technology: a project of the association for educational communications and technology

(2nd ed., Mahwah, NJ: Lawrence Erlbaum Associates, 571-582, 2003).

[2] H. McLellan, Virtual realities. In D. H. Jonassen (Ed.), Handbook of research for educational communications and technology: a project of the association for educational communications and technology (2nd ed., Mahwah, NJ: Lawrence Erlbaum Associates, 461-497, 2003).

[3] C. Youngblut, Educational uses of virtual reality technology (Institute for Defense Analyses: 1998), retrieved on July 25, 2006 from http://www.hitl.washington.edu/scivw/youngblut-edvr/D2128.pdf

[4] J.C.G.M. van Rooij. Research on simulator-based training and instruction strategies, Proc. of the HFES Europe Chapter annual Meeting,, 73-81. Dortmund, Germany, November 1994.

[5] W. Schneider, Training high-performance skills: fallacies and guidelines, Human Factors, 27, 1985, 285-300.

[6] P. Wolffelaar, S. Bayarri, and I. Coma, Script-based definition of complex scenarios. Proc. of the 4th Driving Simulation Conference, 353-365. Paris, France, July 7-8, 1999.

[7] L. Jacobson, Welcome to the virtual world. In Richard Swadley (Ed.), On the cutting edge of technology (Carmel, IN: Sams, 69-79, 1993).

[8] 3D-Fahrschule home page: retrieved on July 25, 2006 from http://www.3d-fahrschule.de/

[9] W. van Winsum, and J.E. Korteling, Low-cost simulators 3D: Task analysis for driving simulation (Report No. TM-98A041, Soesterberg, The Netherlands: TNO-Human Factors. 1998).

[10] Y. Miao, Supporting situated learning for virtual communities of practice: representation and management of situated knowledge. Proc. of the 4th IEEE International Conference on Advanced Learning Technologies, 490-494. Joensuu, Finland, September, 2004.

[11] J.S. Brown, A. Collins, and P. Duguid, Situated cognition and the culture of learning, Educational Researcher, 18( 1), 1989, 32-41..

[12] J. Lave, Cognition in practice, (New York: Cambridge, 1988).

[13] I. Shor, Critical teaching and every day life (Chicago: University of Chicago Press, 1987).

[14] R. Richey, Agenda-building and its implications for theory construction in instructional technology. Educational Technology, 37(1), 1997, 34-41.

[15] J. Lave, and E. Wenger, Situated learning (New York: Cambridge, 1991).

[16] A.L. Brown, The advancement of learning, Educational Researcher, 23(8), 1994, 4-12. 
[17] E. Friedman-Hill, Jess, the rule engine for the Java platform. retrieved on July 25, 2006 from http://herzberg.ca.sandia.gov/jess.

[18] T. Lehman, S. McLaughry, P. Wyckoff, TSpaces: the next wave, Proc. $32^{\text {nd }}$ Hawaii International Conference on System Sciences (HICSS-32), 1999. 